\title{
O Caderno De Um Professor \\ E As Suas Relações Com O Saber Matemático
}

\author{
The Notebook Of A Teacher
}

And His Relations With Mathematical Knowledge

\author{
Wagner Rodrigues Valente \\ Universidade Federal de São Paulo - (UNIFESP-SP)
}

\begin{abstract}
Resumo
Este texto analisa um caderno intitulado "Caderno de Prática, Rocha, SP, 1958". Refere-se, provavelmente, a um material fruto de curso ministrado a professores dos primeiros anos escolares. Atém-se às páginas destinadas à "Metodologia da Aritmética", pois há no Caderno várias outras rubricas escolares. Na análise, mobilizam-se categorias como "saber a ensinar", "saber para ensinar", "relação com o saber", dentre outas. O estudo conclui pela existência de uma "matemática para ensinar ensinada" resultado das relações como o saber mantida entre a formação inicial e a docência. Em particular, revela como se constitui a "aritmética para ensinar ensinada" fruto de apropriações de propostas da modernidade pedagógica.
\end{abstract}

Palavras-chave: Caderno escolar. Formação de professores. Aritmética. Educação Matemática.

\begin{abstract}
This text analyzes a notebook entitled "Caderno de Prática, Rocha, SP, 1958". It is probably referring to a course material taught to teachers of the first school years. The pages dedicated to the "Arithmetic Methodology" are used, as there are several other school headings in the Notebook. In the analysis, categories such as "knowledge to teach", "knowledge for teach", "relationship with knowledge", among others are mobilized. The study concludes by the existence of a "mathematics for teach taught" result of the relations as the knowledge maintained between the initial formation and the teaching. In particular, it reveals how "arithmetic for teach taught" is the fruit of appropriations of pedagogical modernity proposals.
\end{abstract}

Keywords: School notebook. Teacher training. Arithmetic. Mathematics Education.

\section{Introdução}

Já há, relativamente, muitos estudos que mostram a importância do uso de cadernos escolares na pesquisa histórica, nas investigações do campo da História da Educação ${ }^{1}$. As motivações desses trabalhos convergem sempre para os mesmos objetivos: aproximarem-se do

\footnotetext{
${ }^{1}$ Um exemplo que pode ser tomado como referência desses estudos está reunido na obra organizada por MIGNOT (2008).
} 
conteúdo da "caixa preta" da escola, das lides que ocorrem no cotidiano das classes. O que se passa no interior das salas de aula? Mais ainda: como a educação escolar se transforma ao longo do tempo?

Os objetivos deste estudo não são diferentes, apenas têm uma especificidade: as aulas onde está presente a matemática, ministradas nos primeiros anos escolares; os processos e dinâmicas das mudanças dessas aulas. E, de modo ainda mais pontual, este texto investiga as relações com o saber, com a matemática. Essas relações podem ser pensadas, inicialmente, de modo lato: tratam-se de relações que se estabelecem entre os saberes de formação dos professores e aqueles ministrados pelos docentes em seu ofício profissional. No caso deste artigo, consideram-se as relações entre formação e docência e, em particular, aquelas que têm em conta os saberes matemáticos.

Em um texto escrito anteriormente fizemos um exercício reflexivo sobre as possibilidades de estudar essas relações com o saber, a partir de cadernos escolares (VALENTE, 2016a). Naquela altura, evocamos os estudos de Bernard Charlot realizados na década de 1990. Esse autor deu status de conceito à noção de "relação com o saber" ("rapport au savoir"). Em sua sistematização teórica o pesquisador francês acabou propondo várias definições sobre o que poderia ser entendido como "relação com o saber". Interessou-nos reter uma delas: "as relações com saber-objeto". Tal relação poderá ser mobilizada na análise das relações entre formação de professores que ensinam matemática e o ensino de matemática propriamente dito. Por "saberobjeto" entende o autor o "saber em si mesmo, na medida em que ele é 'objetivado', isto é, apresentado como um objeto intelectual, como o referente de um conteúdo de pensamento" (CHARLOT, 1997, p. 77).

Quanto à definição das relações com o saber, entendidas aqui como relações com o saber-objeto, lançamos mão, também para este texto, da caracterização dada por Charlot como sendo:

Um conjunto de relações que um sujeito mantém com um objeto, um 'conteúdo de pensamento', uma atividade, uma atividade, uma relação interpessoal, um lugar, uma pessoa, uma situação, uma ocasião, uma obrigação etc., ligadas de algum modo ao aprender e ao saber [...] (CHARLOT, 1997, p. 94).

À vista dos saberes envolvidos na formação de professores, interessa-nos analisar como essa formação, especificamente para o caso da matemática, leva os professores ao ensino de uma determinada matemática nas salas de aula. Em outras palavras, cabe a investigação sobre as relações que se estabelecem entre a matemática presente na formação dos professores e a matemática mobilizada pelos docentes em suas práticas pedagógicas. 
Deseja-se, assim, analisar as relações com o saber (CHARLOT, 1997) do professor que ensina matemática. Tais relações pensadas do ponto de vista do consumo e uso dos saberes matemáticos na ação docente. Consumo e uso tratados nos termos de um "fazer com: usos e táticas" (DE CERTEAU, 1994). Desse modo, advoga-se que a matemática que o professor mobiliza no ensino não pode ser identificada com a matemática de formação que o professorando recebe; será preciso investigar o consumo e uso que o docente faz dessa formação, lida na relação que esse profissional estabelece com o saber. Esse processo de tomar algo dado na realidade objetiva, transformá-lo sob a perspectiva do sujeito que o consome e o devolve numa determinada forma de uso, tem no conceito de apropriação a sua precisa caracterização, sistematizada nos estudos de Roger Chartier, na História Cultural:

a apropriação, tal como a entendemos, tem por objetivo uma história social das interpretações, remetidas para as suas determinações fundamentais (que são sociais, institucionais, culturais) e inscritas nas práticas especificas que as produzem. Conceder deste modo atenção às condições e aos processos que, muito concretamente, determinam as operações de construção do sentido (na relação de leitura, mas em muitas outas também) é reconhecer, contra a antiga história intelectual, que as inteligências não são desencarnadas, e , contras as correntes de pensamento que postulam o universal, que as categorias aparentemente mais invariáveis devem ser construídas na descontinuidade das trajetórias históricas (CHARTIER, 1990, p. 26-27).

\section{A MATEMÁTICA PARA ENSINAR: Algumas Considerações}

A “matemática para ensinar" e a "matemática a ensinar" compõem um par de conceitos advindos de apropriações de pesquisas que vêm sendo realizadas pela Equipe de Pesquisa em História das Ciências da Educação (ERHISE) da Universidade de Genebra, na Suíça ${ }^{2}$. Os referenciais teórico-metodológicos elaborados por esses pesquisadores apontam, por meio de estudos sócio-históricos, que é possível, na formação de professores, considerar dois tipos de saberes. Um primeiro tipo caracterizado como aqueles ditos "saberes a ensinar". Tais saberes têm referência nas disciplinas científicas e dizem respeito ao objeto de ensino da docência. De outra parte, há os "saberes para ensinar". Neste caso, tem-se um rol de saberes próprios do ofício docente, constituindo as suas ferramentas de trabalho na tarefa que têm os professores de formar pessoas. Desse modo, ao considerar essas sistematizações sobre os saberes, trabalhamos com a hipótese teórica de que há a "matemática a ensinar" como um saber advindo do campo matemático, reunindo uma gama de conteúdos que devem ser aprendidos por aqueles que estão

\footnotetext{
${ }^{2}$ Informações mais detalhadas sobre esse grupo de pesquisa, dirigido pela professora Rita Hofstetter podem ser consultadas no endereço: https://www.unige.ch/fapse/recherche/groupes/ssed/culture-organisation/erhise/
} 
em processo de formação. E, assim sendo, a depender do nível de ensino, tais conteúdos matemáticos, por exemplo aqueles da Educação Básica, têm caráter de um saber de cultura geral. Trata-se de uma matemática que deve participar da formação de todo cidadão escolarizado. De outra parte, admitimos a existência da "matemática para ensinar" correspondente a um saber específico, um saber do profissional da docência, uma ferramenta do ofício de ser professor. Elaborada historicamente em articulação com a matemática a ensinar, a "matemática para ensinar" mais recentemente tem sido objeto de pesquisas. Será a configuração desse saber específico dos professores, um dos elementos que caracterizam a profissão docente (VALENTE, 2016b).

\section{UM CADERNO ESCOLAR: “Caderno De Prática, Rocha, SP, 1958”}

"Caderno de Prática, Rocha, SP, 1958" - assim se intitula, a partir de busca no Repositório da $\mathrm{UFSC}^{3}$, o material empírico utilizado para análise neste texto. Em verdade, pela ficha de metadados tem-se muito poucas informações sobre esse material. Tão somente que:

O caderno de Prática de Thereza P. Rocha foi utilizado, provavelmente, em uma instituição de formação de professores, do Curso de Aperfeiçoamento (formação de professores já em exercício), da disciplina de Metodologia da Aritmética. Título: Caderno de Prática: Metodologia da Aritmética e Metodologia da Linguagem; Orientação didática para as aulas de Geografia; Metodologia; Metodologia das Ciências Físicas e naturais; Centro de Interesses; Desenho; Dobradura, Tecelagem; Modelagem. Caderno de capa estampada em preto e amarelo, pautado, espiral, não há indicação do fabricante do caderno. Há diversas anotações no final do caderno, inclusive receitas de comidas, listas de pessoas, Estatísticas. Dimensões do caderno não registradas. Este exemplar está disponível no Centro de Memória da Educação - Universidade de São Paulo, Coleção Cadernos. (ver: https://repositorio.ufsc.br/xmlui/handle/123456789/163509)

\footnotetext{
${ }^{3} \mathrm{O}$ repositório de conteúdo digital da Universidade Federal de Santa Catarina possui uma pasta com documentação digitalizada de uma quantidade significativa de documentos que poderão ser utilizados como fontes para a história da educação matemática. Há livros, documentações oficiais, revistas pedagógicas, cadernos de alunos e professores. Trata-se de um espaço público de consulta, aberto na internet no endereço: https://repositorio.ufsc.br/handle/123456789/1769
} 


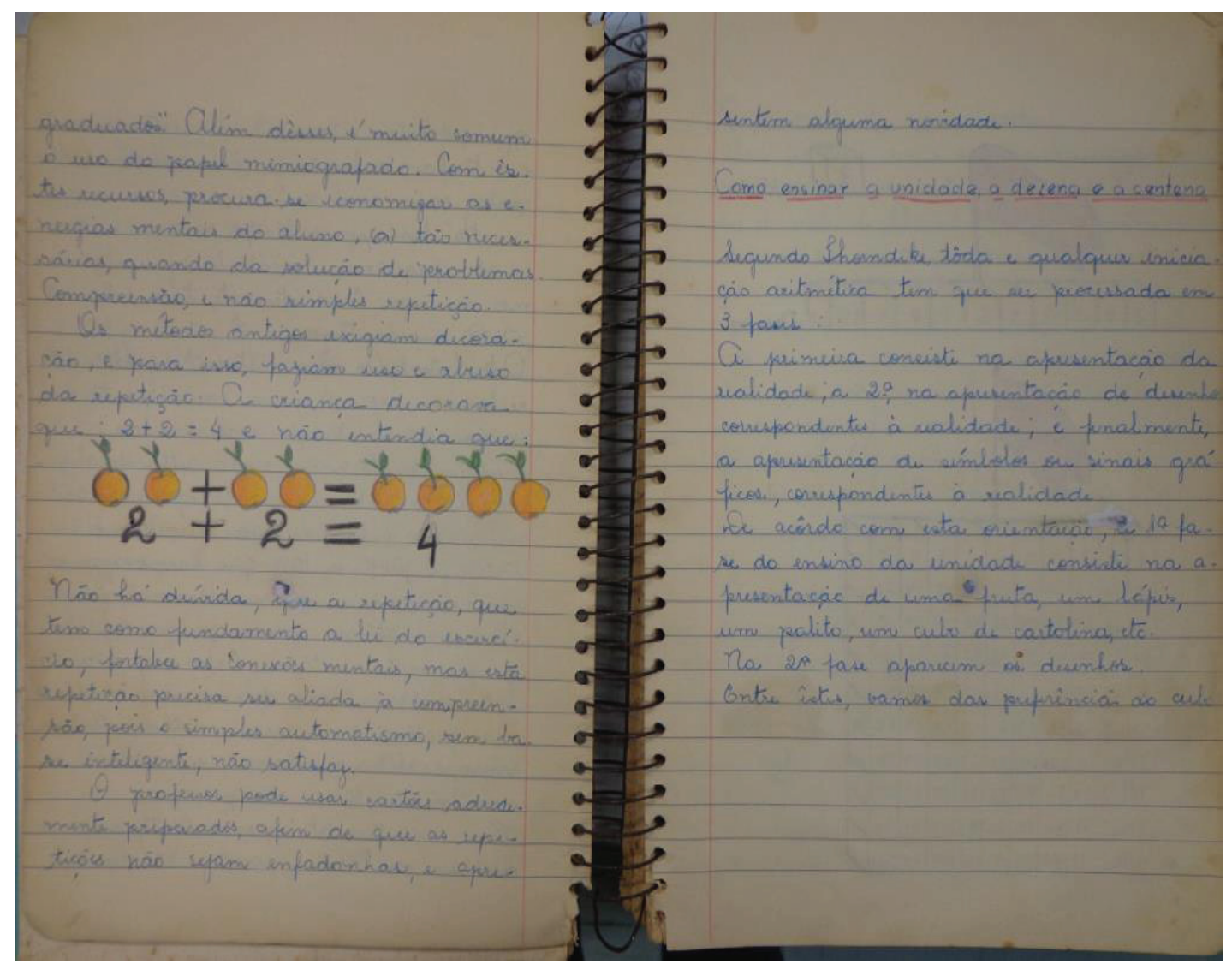

Figura 1: Páginas do "Caderno de Prática" Fonte: https://repositorio.ufsc.br/handle/123456789/163509

Adotemos, assim, que o caderno tem por conteúdos anotações de professor que participa de um Curso de Aperfeiçoamento, isto é, tem-se um material que referenciou uma "formação continuada", para usar termos dos dias de hoje. De outra parte, vamos nos ater apenas na parte do material reservada à Aritmética. E é justamente esse conteúdo matemático que está presente nas primeiras páginas do caderno. Sob o título de "Metodologia da Aritmética", o caderno apresenta em suas linhas os subtítulos a saber: "Os diversos métodos do ensino", "Como ensinar a unidade, a dezena e a centena", "A organização do aprendizado", "Representação gráfica", "O ensino da soma e subtração", "O ensino da multiplicação e divisão" e, por fim, "Recursos didáticos recomendados para as aulas de Aritmética".

Em "Os diversos métodos do ensino" lê-se no caderno um contraponto que seguirá pelas páginas seguintes das anotações do curso de aperfeiçoamento: as práticas consideradas ultrapassadas versus as novas práticas, as práticas modernas para o ensino de aritmética. E o autor de referência mencionado nas orientações metodológicas para o ensino da Aritmética é 
Edward Lee Thorndike (1874-1949)4, por meio de seu livro "A nova metodologia da aritmética", obra que circulou desde a década de 1930 até finais dos anos 50, pelo menos ${ }^{5}$.

O mote para a proposição do aperfeiçoamento docente, àquele tempo (1958), é o mesmo utilizado por Thorndike em sua obra ${ }^{6}$. Ao longo dos capítulos do livro, o autor estadunidense sempre utiliza o expediente de contrapor o que compreendia sobre o passado do ensino de aritmética e as novas propostas, oriundas da moderna perspectiva de tratar o tema.

Nas anotações relativas aos métodos, o Caderno de Prática apresenta a comparação entre o método dedutivo, considerado tradicional, e a moderna pedagogia que se utiliza do método indutivo. Nas anotações do caderno, há a tentativa de ilustrar o processo dedutivo por meio de um exemplo de subtração entre dois números. O que possivelmente era a intenção do professor do curso de aperfeiçoamento era evidenciar o quão mecanicamente se ensinavam as operações aritméticas, buscando apoio em Thorndike, para afirmar a necessidade de que houvesse cálculos mais próximos da realidade, com situações do cotidiano e, ainda, com valores numéricos não excessivamente grandes. Pelas anotações colocadas no caderno pouco se compreende o significado dos métodos dedutivos e indutivos para ensino de aritmética. No entanto, as linhas escritas no caderno ligam diretamente o método dedutivo à escola tradicional; e o indutivo, à nova metodologia.

Sobre o mesmo tema - métodos de ensino - Thorndike dedica o Capítulo III de seu livro. Intitulado "Teoria e Explicações", o autor aborda os métodos dedutivo e indutivo. Claramente se posiciona a favor do método indutivo. No entanto, pondera que:

(...) apesar das explicações dedutivas, tais como eram usadas, não levarem à compreensão racional das regras e dos processos, tal compreensão é indispensável e possível, isto é, (...) é preciso não abandonar o aluno a uma memorização cega e automática do que tem de fazer (1936, p. 59).

Desse modo, no caso do livro de Thorndike, não há a polaridade escola tradicional (método dedutivo) versus escola moderna (método indutivo), como o que está posto no caderno de anotações do curso de aperfeiçoamento.

Ainda compondo o item relativo aos métodos, tem-se observações sobre os problemas

\footnotetext{
${ }^{4}$ Santos (2006) em sua tese de doutoramento defende que Edward Lee Thorndike conformou um novo padrão pedagógico para o ensino de Matemática nas primeiras décadas do século XX nos Estados Unidos.

${ }^{5}$ Correia \& Silva (2002) indicam, em estudo sobre manuais pedagógicos, que Thorndike constituiu autor de referência desde os anos 1930 até a década de 1950. Nesta última década, houve proliferação de compêndios acerca de metodologia e prática de ensino, no dizer desses autores. Também a tese de Brolezzi (2009) informa que "A nova metodologia da aritmética” foi indicada nos programas do Instituto de Educação de São Paulo, nos anos 30, bem como fazia parte da bibliografia do curso de Didática Especial da Matemática, em 1954.

${ }^{6}$ O livro "A nova metodologia da Aritmética", foi publicado em português, em 1936. Já há alguns estudos que se ocuparam de analisar tal obra. Dentre esses trabalhos cite-se: Santos (2006), Brolezzi (2009) Marques (2013).
} 
aritméticos. Algo interessante surge, pois, dizendo-se apoiar em Thorndike, as linhas anotadas no caderno enfatizam a necessidade de uso de materiais que já deveriam trazer enunciados dos problemas, que não deveriam ser copiados pelos alunos, pois gerariam desinteresse e tornariam a atividade enfadonha. Assim, caberia o uso de "cadernos graduados", substituindo-se o processo de cópia pelos alunos, dos enunciados dos problemas.

Antes porém dessas linhas sobre a conveniência de uso de cadernos que já tragam os enunciados dos problemas, o Caderno de Prática dá exemplo de problemas que eram considerados satisfatórios, mas que na atualidade (de final da década de 1950) não mais deveriam ser formulados aos alunos: "Alice tinha 3/8 de um mil réis, Berta 11/16, Maria 3/25 e Nina 3/4. Quanto possuíam juntas?". A seguir ao exemplo, a frase "Só num hospício um problema com estas características poderia aparecer" atribuída a Thorndike.

A respeito dos problemas, em sua obra, Thorndike discorre longamente sobre o tema. No que diz respeito à questão do interesse e motivação dos alunos e a escrita dos problemas, o autor estadunidense pontua que "o simples trabalho de copiar é suficiente para matar o prazer de pensar". Além disso, o autor recomenda que nos compêndios "grande parte dos exercícios de cálculo devem ser dispostos de tal modo que a criança colocando uma folha de papel sob uma linha ou ao lado de uma coluna de exercícios, tenha apenas o trabalho de escrever as respostas nesta folha" (THORNDIKE, 1936, p. 28). De outra parte, por certo, o exemplo tomado e anotado no Caderno de Prática, bem como a frase atribuída a Thorndike tem origem no texto de sua obra onde se lê: "problemas como os acima citados, em situação real, só podem aparecer num hospital de alienados" (THORNDIKE, 1936, p. 14).

No subtítulo "Como ensinar a unidade, a dezena e a centena", lê-se no caderno:

Segundo Thorndike toda e qualquer iniciação aritmética tem que ser processada em 3 fases. A primeira consiste na apresentação da realidade; a $2^{\mathrm{a}}$., na apresentação dos desenhos correspondentes à realidade; e, finalmente, a apresentação de símbolos ou sinais gráficos correspondentes à realidade.

Este item parece não ter paralelo ao texto de Thorndike, constitui-se numa apropriação das discussões do autor estadunidense, de modo a orientar professores a "concretizar" o ensino, enfatizando a necessidade de iniciar todo o trabalho da aritmética a partir de situações reais da vida.

O subitem que segue intitula-se "A organização do aprendizado", título idêntico ao utilizado por Thorndike em sua "A nova metodologia da aritmética”. Lê-se, no Caderno de Prática, que ao seguirem-se as orientações modernas, aquelas de Thorndike, não caberia, como na escola tradicional a graduação do ensino, segundo uma lógica da aritmética. Por exemplo, 
iniciarem-se os estudos pela adição, depois subtração, multiplicação e, por fim, divisão. Há que serem ensinadas todas as operações concomitantemente... De fato, no texto de Thorndike tal referência não está presente. $\mathrm{O}$ autor não advoga o ensino concomitante. $\mathrm{O}$ que nos parece, na apropriação feita pelo Caderno de Prática, é a tentativa de enfatizar que as operações deveriam surgir de situações reais. De outra parte, é interessante notar o que concluem as linhas do Caderno, textualmente revelando que: “A cadeira, no entanto, prefere, embora dando noção das 4 operações, ensinar a soma e subtração, inicialmente e, posteriormente, a multiplicação e divisão (...)".

A seguir a essas ponderações e indicações, dizem as linhas do Caderno: "Deixemos agora, pelo menos por algum tempo, a obra de Thorndike, e abracemos as concepções de Pestalozzi a respeito do ensino da iniciação aritmética".

A observação sobre voltarem-se os olhos para os ditames de Pestalozzi incide nos mesmos passos atribuídos anteriormente a Thorndike: "reconhecer as coisas concretas objetos; em seguida, reconhecimento através de desenhos - bolas etc.; e, finalmente, procurase alcançar objetos ausentes, deixando-se o campo da concretização para alcançar o campo da abstração (...)". Tais linhas constituem introdução ao que o Caderno revela ser importante para o professor associar a escrita dos números à "forma gráfica" expressa por bolinhas, como pedras de um dominó, atribuindo tal expediente a Pestalozzi. Tais discussões incluem-se no subitem do Caderno de Prática intitulado "Representação gráfica".

Seguem-se no caderno de anotações do curso de aperfeiçoamento orientações sobre o ensino das quatro operações fundamentais. Tratando em separado da adição e subtração; posteriormente, da multiplicação e divisão, como mencionado anteriormente. No primeiro caso, o professor é orientado, tendo por base, segundo o Caderno, as assertivas de Pestalozzi, a representar graficamente as quantidades que comporão exemplos de operações: desenhos de laranjas, por exemplo. Assim, duas laranjas somadas a três laranjas irão compor cinco laranjas. Dos desenhos delas, passa-se para a escrita numérica da operação. No caso da multiplicação e divisão, a escrita do Caderno orienta os professores a começarem pela divisão, tratada como uma operação mais simples que a multiplicação.

Por último item das orientações, o Caderno de Prática apresenta os "Recursos didáticos recomendados para as aulas de Aritmética". No rol desses recursos tem-se: a árvore do cálculo, o uso de palitos, os quadros de Parker $^{7}$, cartazes, bonecos, mapas, jogo de cartelas para a

\footnotetext{
${ }^{7}$ Estudos mais aprofundados sobre o uso desses materiais podem ser lidos no texto PINHEIRO; VALENTE (2015).
} 
tabuada. Tais recursos bem revelam o ecletismo das orientações dadas no curso de aperfeiçoamento. Mostram materiais ícones de diferentes propostas presentes na modernidade pedagógica.

\section{O CURSO DE APERFEIÇOAMENTO DO ENSINO DE ARITMÉTICA: As Relações Com O Saber Na Produção De Um Amálgama Da Modernidade Pedagógica}

$\mathrm{Na}$ investigação dos processos e dinâmicas que se estabeleceram historicamente para a constituição da matemática para ensinar, há se ter em conta as suas apropriações. Elas poderão ser lidas nos cadernos escolares, nos cadernos dos professorandos, ou mesmo nos cadernos dos professores que participaram de formações continuadas. Este último caso leva ao material estudado neste texto. O Caderno de Prática tem por conteúdo reelaborações da professora Thereza Pereira Rocha, do curso de aperfeiçoamento, onde foi ela participante.

Apesar de termos em conta que os conteúdos lidos no Caderno de Prática constituem reelaborações, apropriações feitas pela professora Thereza, é possível afirmar que tais cadernos indicam, de modo o mais próximo, as ferramentas profissionais que foram transmitidas aos futuros docentes, ou mesmo aos professores em formação continuada, por meio de "cursos de aperfeiçoamento". Os cadernos nos dão pistas do saber ensinado. No caso estudado, temos pistas sobre a "matemática para ensinar ensinada". Uma matemática do "fazer com: usos e táticas". E, neste caso, a formação de professores poderá ser vista como um verdadeiro consumo cultural, posto no sentido dado por De Certeau: o consumidor não identificado ou qualificado conforme os bens que consome, os bens culturais de sua formação, "entre ele (que deles se serve) e esses produtos (indícios da 'ordem' que lhe é imposta), existe o distanciamento mais ou menos grande do uso que faz deles (2003, p. 95).

O manual de Thorndike, que teve grande circulação internacional sistematizou, objetivou uma aritmética para ensinar, no esforço realizado pelo autor e suas pesquisas, aglutinadoras da psicologia em voga. A obra elabora uma crítica ao saber professoral considerado tradicional de compêndios que pressupunham lógicas diferentes daquelas indicadas pelo estudo da criança e seu desenvolvimento. As apropriações decorrentes do uso desse manual em cursos de formação de professores - como é o caso do caderno analisado remetem a uma outra categoria, para além daquela considerada como uma "aritmética para ensinar". As linhas escritas no Caderno de Prática dizem mais respeito a "uma aritmética para ensinar ensinada", como se mencionou em linhas anteriores. Envolvem elementos que permitem discutir a relação com o saber que o formador manteve com a matemática para ensinar 
de sua formação, revelam suas estratégias e táticas (DE CERTEAU, 2003) no uso de elementos que participaram de sua formação, agora mobilizados para o ensino.

A relação com o saber mantida pelo formador com a matemática para ensinar pode, assim, ser lida no Caderno de Prática; e a análise revela um amálgama. Mostra um compósito de obras e autores com perspectivas pedagógicas diferentes presentes nas orientações metodológicas tratadas no curso de aperfeiçoamento ministrado. Mas, tal organização do curso parece conduzir-se por uma lógica: a necessidade de indicações práticas para a docência dos conteúdos da aritmética. E esses conteúdos são, sobretudo: os problemas aritméticos, as operações e a tabuada. A cada um desses temas, indicações de como o professor deverá proceder, tendo em conta referências de saberes para ensinar, de aritméticas para ensinar, elaborados em tempos diversos e materializadas em dispositivos que poderão auxiliar os professores. Para o ensino de problemas aritméticos, buscou-se Thorndike; para as operações, elementos da própria experiência desenvolvida pelo formador, apropriados de processos intuitivos; para o sistema de numeração, para as tabuadas referências a Pestalozzi.

Como bem sintetizaram os pesquisadores Jorge Ramos do Ó e Luís Miguel Carvalho, a modernidade pedagógica poderá ser pensada como fruto da emergência da pedagogia como campo científico autônomo. E esse processo condensou-se historicamente num curto período de tempo: da década de 1880 a finais dos anos 1920 (RAMOS DO Ó; CARVALHO, 2009, p. 37). Assim, com esse marco referencial, torna-se possível utilizar-se a expressão - modernidade pedagógica - para análise de inúmeras e diferentes proposições que foram gestadas nesse tempo de algumas poucas décadas.

Advogar a modernidade pedagógica para processos, didáticas e propostas de ensino pode, desse modo, implicar na reunião de elementos que tiveram expressão a partir de 1880. E, parece ser esse o caso ocorrido no curso de aperfeiçoamento, lido nas páginas do Caderno de Prática, na Metodologia da Aritmética redigida pela professora Thereza. Thorndike, Pestalozzi, Parker são expressões desse período, mesmo sendo referências muito diferentes para o ensino de matemática. Cada um, a seu tempo, elaborou, sistematizou uma matemática para ensinar nos primeiros anos escolares. A matemática para ensinar ensinada, lida no Caderno de Prática, amalgamou essas modernas referências.

\section{Referências}

BROLEZZI, V. L. F. O processo de disciplinarização da Metodologia do Ensino de Matemática. Tese de doutorado, FEUSP, 2009. 
CHARLOT, B. Du rapport au savoir - Éléments pour une théorie. Paris: Anthropos, 1997.

DE CERTEAU, M. A invenção do cotidiano. 1. As artes de fazer. Rio de Janeiro, Petrópolis: Editora Vozes, 2003.

CORREIA, A. C. L.; SILVA, V. B. Manuais Pedagógicos - Portugal e Brasil - 1930 a 1971 Produção e Circulação Internacional de Saberes Pedagógicos. Caderno Prestige, 13. Coimbra, Portugal: EDUCA, 2002.

MARQUES, J. A. O. Manuais pedagógicos e as orientações para o ensino de matemática no curso primário em tempos de Escola Nova. Dissertação de Mestrado. São Paulo: Programa de PósGraduação em Educação e Saúde na Infância e na Adolescência, 2013.

MIGNOT, A. C. V. (org.) Cadernos à vista - Escola, memória e cultura escrita. Rio de Janeiro: Editora da UERJ, 2008.

PINHEIRO, N. V. L.; VALENTE, W. R. Chega de decorar a tabuada! As Cartas de Parker e a Árvore do Cálculo na ruptura de uma tradição. Educação Matemática em Revista, RS. V. 1, p.22-37, 2015.

RAMOS DO Ó, J.; CARVALHO, L. M. Emergência e circulação do conhecimento psicopedagógico moderno (1880-1960) - estudos comparados Portugal - Brasil. Lisboa: EDUCA, 2009.

SANTOS, I. B. Edward Lee Thorndike e a conformação de um novo padrão pedagógico para o ensino de matemática (Estados Unidos, primeiras décadas do século XX). Tese de doutorado. PUC/SP, 2006

THORNDIKE, E. L. A nova metodologia da Aritmética. Trad. Anadyr Coelho, Porto Alegre: Editora Livraria do Globo, 1936.

VALENTE, W. R. Relações entre a formação e a docência em Matemática: perspectivas de análise com o uso de cadernos escolares. REMATEC - Revista de Matemática, Ensino e Cultura (UFRN). V. 11, p. 6-19, 2016a.

VALENTE, W. R. O Saber: uma questão crucial para a institucionalização da Educação Matemática e profissionalização do educador matemático. Perspectivas da Educação Matemática, v. 9, p. 460-478, $2016 \mathrm{~b}$. 